\title{
A quantitative analysis of the relationship between absorbed and applied phosphorous and their contribution to seed production in soybeans under various applied nitrogen conditions
}

Jin Kakiuchi ( $\nabla$ j3kakiuc@nodai.ac.jp)

Tokyo University of Agriculture - Atsugi Campus: Tokyo Nogyo Daigaku - Atsugi Campus https://orcid.org/0000-0003-2553-9670

Tohru Kobata

Faculty of Life and Environmental Science, Shimane University

Research Article

Keywords: Fertilizer, Model, Nitrogen, Nodulation, Phosphorus, Soybean

Posted Date: January 25th, 2022

DOl: https://doi.org/10.21203/rs.3.rs-1259913/v1

License: (c) (i) This work is licensed under a Creative Commons Attribution 4.0 International License. Read Full License 


\section{Abstract \\ Aims}

This study aimed to model the relationship between assimilated $\left(P_{A}\right)$ and applied $\left(P_{F}\right)$ phosphorus under diverse nitrogen applications $\left(N_{F}\right)$, and to determine the contribution of $\mathrm{P}$ to $\mathrm{N}$ assimilation $\left(\mathrm{N}_{\mathrm{A}}\right)$ and seed production in soybeans [Glycine max (L.) Merr.], as this has not been done before.

\section{Methods}

Over three years, pot experiments were conducted using nodulated [Lee(+)] and non-nodulated isoline [Lee(-)] soybeans under multiple levels of basal-dressed $P_{F}$ and top-dressed $N_{F}$ from R2 to R7.

\section{Results}

$P_{A}$ in each $N_{F}$ was represented by a function of $P_{F}$ as a straight line with a positive slope and an intercept $\left(P_{S}\right.$, soil $\left.P\right)$ connecting with a ceiling line of constant height. The slope $\left[S L O P E=\left(P_{A}-P_{S}\right) / P_{F}\right]$, which represented the efficiency of $P_{F}$ usage for $P_{A}$, asymptotically increased with $N_{F}$. As a result, $P_{A}$ was represented by a single function of $P_{F} \times S L O P E$, which consisted of slope $=1$ and a ceiling across different $N_{F}$ rates. Seed production each year was explained by $\mathrm{N}_{\mathrm{A}}$ regardless of $\mathrm{P}_{\mathrm{A}}$ for both nodulation types, although responses of seed yield to $\mathrm{P}_{\mathrm{A}}$ in Lee(-) differed due to $\mathrm{N}_{\mathrm{A}} \cdot \mathrm{P}_{\mathrm{A}}$ asymptotically increased the maximum $\mathrm{N}_{\mathrm{A}}$ and $\mathrm{N}$ fixation by nodulation which were approximated by the $\mathrm{N}$ quantitative model.

\section{Conclusion}

$P_{A}$ can be represented as a function of $P_{F}$ by excluding $P$ retained in soils, which is influenced by $N_{F}$. Accordingly, $P_{A}$ effects seed production via $\mathrm{N}_{\mathrm{A}}$ behavior determined by fertilizer, soil and fixed $\mathrm{N}$.

\section{Introduction}

Phosphorus is one of the essential nutrients that determine seed yield in soybeans [Glycine max (L.) Merr.] (White and Veneklaas 2012). For instance, high P levels are required for nitrogen fixation $\left(\mathrm{N}_{\mathrm{FIX}}\right)$ as a dominant nitrogen source for the seed production (Schulze et al. 2006), because $\mathrm{N}_{\mathrm{FIX}}$ consumes large amounts of energy, and energy-generating metabolism depends on the availability of P (Israel 1987; Theodorou and Plaxton 1993). In addition, $\mathrm{P}$ is considered to have important effects on the development of roots, in terms of their proliferation, the number and weight of nodules, and nodule activity, which determine $\mathrm{N}$ fixation capacity in legumes (Cassman et al. 1980; Chaudhary and Fujita 1998; Chaudhary et al. 2008; de Mooy and Pesek 1966; Konno et al. 1990; Matsunaga and Matsumoto 1984; Schulze et al. 2006; Singh et al. 2005). However, not all applied $P$ from fertilizer is absorbed by plants, because parts of $P$ are fixed in soil depending on the soil phosphate absorption coefficient, which is strongly influenced by soil types (Auxtero et al. 2008; Kitou et al. 2009; Rubaek and Sibbesen 1995; Stewart and Tiessen 1987). Furthermore, some of the $P$ will be retained in the soil if root distribution is insufficient to extend into fertilized areas (Silberbush and Barber 1983). Basal-dressing $P$ fertilizer that is added to the soil at sowing time will not move much from the positions to which it was applied, especially in soil with a high $\mathrm{P}$ fixation capacity (Sleight et al. 1984). Therefore, $\mathrm{P}$ absorption by plants is highly dependent on root contact with soil P, as well as P fixation by the soil phosphate absorption coefficient (Caassen and Barber 1976; Marschner 1995).

Root length, which is closely related to root contact with soil P, significantly increases with increasing $\mathrm{N}$ application in soybeans (Arima et al. 2000). Significant increases in root length due to $\mathrm{N}$ application, sometimes without changes in root weight, have been observed in many plant species (Sathiyavani et al. 2017). Therefore, it is possible that $\mathrm{N}$ application influences $\mathrm{P}$ absorption, depending on root length and distribution. Hence, $\mathrm{P}$ absorption from applied $\mathrm{P}$ should be analyzed with known $\mathrm{N}$ conditions, where the interaction effect between $\mathrm{P}$ and $\mathrm{N}$ fertilizers on these nutrient absorptions by plants was observed (Marschner 1995).

Meanwhile, $\mathrm{N}$ is fundamentally a major yield-limiting factor in soybeans (Sinclair and de Wit 1976), and $\mathrm{N}$ assimilation $\left(\mathrm{N}_{\mathrm{A}}\right)$ explains the variation in yield of many soybean cultivars (Pazderink et al. 1997; Rotundo et al. 2014). However, $\mathrm{N}_{\mathrm{A}}$ does not simply correlate with applied $\mathrm{N}$ $\left(\mathrm{N}_{\mathrm{F}}\right)$, due to a tradeoff between $\mathrm{N}_{\mathrm{FIX}}$ and $\mathrm{N}_{\mathrm{F}}$ (Fujita and Tanaka 1982; Tanaka et al. 1980). 
P fertilizer is derived from phosphate rock, the cost of which has increased due to an increase in P fertilizer use (Cordell et al. 2009). There has been concern that phosphorus demand will outstrip supply within this century if no fundamental changes are made to the current trajectory (Cordell, 2021). To increase the efficiency of $P$ fertilizer usage (assimilated $P$ / supplied $P$ ) to save $P$ fertilizer use, a quantitative analysis of the relationship between assimilated and applied $\mathrm{P}$ is essential. Quantitative relationships between absorbed $\mathrm{P}$ by plants and soil $\mathrm{P}$ relating with the soil phosphate absorption coefficient were indicated in soybean and alfalfa (Aguilar and van Diest 1981) and in rice (Tanikawa 2016). Furthermore, a macro model of the relationship between $P$ absorption and root distribution or structure was proposed for corn plants (Caassen and Barber 1976), kidney bean and six crop species (Föhse et al. 1991). However, a quantitative model that formulates P absorption by plants from applied $\mathrm{P}$ and accounts for the effects of $\mathrm{N}$ application on the $\mathrm{P}$ absorption has not been put forward for soybeans. Therefore, our objectives for this study were to establish a model concept of the quantitative relationship between absorbed and applied $\mathrm{P}$ under various applied $\mathrm{N}$ conditions and to determine the contribution of absorbed $\mathrm{P}$ to $\mathrm{N}$ absorption and seed production in soybeans.

\section{Materials And Methods}

Plant experiments

\section{Plant materials and $\mathrm{P}$ and $\mathrm{N}$ treatments}

The soybean cultivar 'Lee' [Lee(+)] and a non-nodulated isoline of Lee [Lee(-)] were used in the following pot experiments. The pot experiments were conducted in 2016 and 2017 in Setagaya, Tokyo, Japan (35 $64^{\prime}$ N, 139 $63^{\prime}$ E, at 45.9 m asl), and in 2020 in Atsugi, Kanagawa, Japan $\left(35^{\circ} 26^{\prime} \mathrm{N}, 139^{\circ} 20^{\prime} \mathrm{E}\right.$, at $25.7 \mathrm{~m}$ asl). Plants were grown in pots filled with $11 \mathrm{~L}$ of commercially available soil (disinfected and aggregated natural Andosol; Akadama, Hujimi Engei Co., Japan). This soil drains well, has a pH of 5.5 - 6.5, and contains minimal amounts of $\mathrm{N}$ and $\mathrm{P}$. The soil originated from volcanic sediments and thus had a high phosphorus-retention capacity (phosphate absorption coefficient $=10.3-12.4 \mathrm{~g} \mathrm{P} \mathrm{kg}^{-1}$ ). To determine the effect of applied $\mathrm{P}$ and $\mathrm{N}$ on their assimilation, this $\mathrm{P}$ - and $\mathrm{N}$-poor soil was used. Before sowing, magnesium lime $\left(10 \mathrm{~g} \mathrm{pot}^{-1}\right)$ and $\mathrm{KCl}\left(1.15 \mathrm{~g} \mathrm{pot}^{-1}\right)$ were mixed with one of four or five concentrations of $\mathrm{P}(0,1.31,4.37$, or $6.55 \mathrm{~g}$ pot $^{-1}$ in 2016 and 2017, and 0, 0.44, 1.31, 4.37, or $6.55 \mathrm{~g} \mathrm{pot}^{-1}$ in 2020; as superphosphate). These $\mathrm{P}$ treatments, are hereafter referred to as P0, P1, P3, P10, and P15, respectively. Three seeds of each of the soybean isolines (Lee[+] or Lee[-]) were sown in each pot. The sowing date was 14 June in 2016 and 2017, and 23 June in 2020. Two plants were removed at the V2-3 stage (second to third node; Fehr and Caviness 1977), and the remaining plant was left to grow. The plants were sufficiently irrigated by hand spraying throughout the growing season. Liquid fertilizer was applied, providing $0.1 \mathrm{~g}$ of $\mathrm{N}$ per pot as $\left(\mathrm{NH}_{4}\right)_{2} \mathrm{SO}_{4}$, on 18 and 25 July and 1 August in 2016, on 18, 24, and $31 \mathrm{July}$ in 2017, and on 21 and 27 July in 2020.

$\mathrm{N}$ treatments were applied between the full bloom (R2) and beginning maturity (R7) stages (Fehr and Caviness 1977) over 10 weeks during the seed-filling period: from 8 August to 11 October in 2016, from 7 August to 9 October in 2017, and from 4 August to 6 October in 2020. Plants were treated weekly with $0,0.05,0.20$, or $0.80 \mathrm{~g} \mathrm{~N} \mathrm{pot}^{-1}$ in 2016 and 2017, and $0,0.2,0.4,0.8$, or $1.2 \mathrm{~g} \mathrm{~N} \mathrm{pot}^{-1}$ in 2020 , in the form of $\left(\mathrm{NH}_{4}\right)_{2} \mathrm{SO}_{4}$. These $\mathrm{N}$ treatments are hereafter referred to as $\mathrm{N} 0, \mathrm{~N} 0.5, \mathrm{~N} 2, \mathrm{~N} 4, \mathrm{~N} 8$, and N12, respectively. Thus, this experiment consisted of 16 or 25 treatment combinations, incorporating four or five different $\mathrm{P}$ treatments and four or five different $\mathrm{N}$ treatments. The experimental design was completely randomized and there were three replications.

Sampling and measurements

Individual plants were sampled at the R8 (full maturity) stage (Fehr and Caviness 1977). The numbers of nodes, total pods, ripening pods, and seeds were counted for each plant. The stems, leaves, pod shells, and seeds were separated from each sample, dried at $80^{\circ} \mathrm{C}$ for $48 \mathrm{~h}$, and then weighed. During the growing period, abscised organs were carefully gathered two or three times per week, dried at $80^{\circ} \mathrm{C}$ for $48 \mathrm{~h}$, and then weighed. These weights were added to the dry sample weights to obtain a total dry weight for each organ type.

Each organ was milled and dissolved using a sulfuric acid-hydrogen peroxide digestion method (Matsunaga and Shiozaki 1989). The P and N content of each organ were then determined using the molybdenum blue method (Murphy and Riley 1962) and the distillation-titration method (Nelson and Sommers 1973), respectively.

Modelling and statistical analysis

Models of the relationship between assimilated $\mathrm{P}$ and applied $\mathrm{P}$

Three cases of the relationship between $P_{A}$ and $P_{F}$ can be predicted (Fig. 1, left graph). Case 1 is that $P_{A}$ continuously and linearly increases with $P_{F}$, where the slope $=1$ (no phosphorus retention and no remaining $P$ in soils) and all $P_{F}$ is apparently absorbed by plants, and $P_{A}$ at $P_{F}=$ 0 represents available phosphate in the soil $\left(P_{S}\right)$. Case 2 is that $P_{A}$ increases linearly with $P_{F}$ with a slope lower than 1 and an intercept of $P_{S}$ 
when $P_{F}$ is partially fixed by and/ or retained in the soil. Case 3 is that the increasing $P_{A}$ in Case 2 has a ceiling; this relationship depends on Blackman's law (Thornley 1976), including observations of the relationship between $\mathrm{N}_{\mathrm{A}}$ and $\mathrm{N}_{\mathrm{F}}$ (Kakiuchi and Kobata 2017). In Cases 1 and 2 and the phase below the ceiling in Case 3 , the slope [SLOPE $=\left(P_{A}-P_{S}\right) / P_{F}$ of the line representing the relationship between $P_{A}$ and $P_{F}$ with an intercept of $P_{S}$ can be used to represent $P_{F}$ use efficiency for $P_{A}$. The efficiency would decrease with increasing $P$ fixation in soil or retained $P$ in soil due to insufficient contact of roots with soil. Here, $P_{F} \times$ SLOPE represents the actual available $P$ that is absorbed by plants.

Three cases of the relationship between $P_{A}$ and $P_{F}$ can be represented by two simple types of lines whereby $P_{F}$ is changed to $P_{F} \times S L O P E$ (Fig. 1, middle graph). Furthermore, the relationship between $P_{A}$ and $P_{F} \times$ SLOPE can be normalized to form a relative relationship between $x=$ $\left(P_{F} \times\right.$ SLOPE $) / P_{A m a x}$ and $y=\left(P_{A}-P_{S}\right) / P_{A m a x}$, where $P_{A m a x}$ is the maximum $P_{A}$; in Cases 1 and $2, y=x$ limited by $y=1$ and in Case $3, y=x$ when $x \leq 1$ and $y=1$ when $x>1$ (Fig. 1, right graph).

Estimation of $\mathrm{N}_{\mathrm{A}}$ and $\mathrm{N}_{\mathrm{FIX}}$ using a quantitative $\mathrm{N}$ model

To estimate $\mathrm{N}_{\mathrm{S}}$, the maximum $\mathrm{N}_{\mathrm{A}}$, and $\mathrm{N}_{\mathrm{FIX}}$ in soybeans, a quantitative $\mathrm{N}$ model indicating the relationship between $\mathrm{N}_{\mathrm{A}}$ and $\mathrm{N}_{\mathrm{F}}$ was used for each $P$ application rate (Fig. 2, upper graph) (Kakiuchi and Kobata 2017). The relationship between $N_{F}$ and $N_{A}$ was incorporated into the model to estimate the maximum $\mathrm{N}_{\mathrm{A}}\left(\mathrm{N}_{\mathrm{Amax}}\right)$ and $\mathrm{N}_{\mathrm{FIX}}$. For Lee(-), $\mathrm{N}_{\mathrm{A}}$ in the $\mathrm{N} 0$ treatment represented $\mathrm{N}_{\mathrm{S}}$, and $\mathrm{N}_{\mathrm{A}}$ from the highest $\mathrm{N}$ treatment represented $\mathrm{N}_{\text {Amax }}$. However, $\mathrm{N}_{\mathrm{A}}$ of the P0 treated Lee(-) plants was much lower than the other $\mathrm{P}_{\mathrm{F}}$ treatments, as a result of extremely poor growth due to the negligible quantities of $P$ in the used soil. Therefore, for Lee(-) plants, $N_{A}$ of the N0 at P15 treatment represented $N_{S}$ (Fig. 2 , lower graph). From the fit lines in the model, the maximum $\mathrm{N}_{\mathrm{FIX}}$ under nonfertilized conditions $\left(\mathrm{N}_{\mathrm{FIXmax}}\right), \mathrm{N}_{\mathrm{Amax}}, \mathrm{N}_{\mathrm{S}}$, and the rate (s - 1) of reduction of $\mathrm{N}_{\mathrm{FIX}}$ due to increasing $\mathrm{N}_{\mathrm{F}}$ were estimated. The goodness-of-fit of the observed data to the model was evaluated using the coefficient of determination $\left(r^{2}\right)$.

\section{Statistical analysis}

Differences between treatments were considered significant if $p$ values calculated by Tukey's test were $<0.05$. The least-squares method was used to fit curves, and the coefficients of determination $\left(r^{2}\right)$ and their associated $p$ values were calculated to assess the goodness-of-fit of the models. Multiple regression analysis was conducted to determine the contributions of $\mathrm{N}_{\mathrm{A}}$ and $\mathrm{P}_{\mathrm{A}}$ to seed production. The statistics software Excel Toukei 2012 (Social Survey Research Information, Tokyo, Japan) was used to conduct the statistical analysis.

\section{Results}

The relationship between $\mathrm{P}_{\mathrm{A}}$ and $\mathrm{P}_{\mathrm{F}}$

$P_{A}$ increased linearly with $P_{F}$ from 0 to $2-3$ g pot $^{-1}$ and reached a ceiling when approximately over the values of $P_{F}$ in all $N_{F}$ treatments, for both nodulation types and all three experimental years, although the value of $\mathrm{P}_{\mathrm{A}}$ at the ceiling differed depending on $\mathrm{N}_{\mathrm{F}}($ Fig. 3 ). Therefore, Case 3 in our predicted model most fitted the relationship between $P_{A}$ and $P_{F}$ (Fig. 1). When the SLOPE $\left[\left(P_{A}-P_{S}\right) / P_{F}\right]$ was calculated from a phase of the linear relationship between $P_{A}$ and $P_{F}$ for the lower $P_{F}$ values $\left(<2\right.$ g plant $\left.^{-1}\right)$, the SLOPE increased with $N_{F}$ for both nodulation types across the three experimental years, although the maximum SLOPE differed among experimental years (Fig. 4).

The relationship between $\mathrm{P}_{\mathrm{A}}$ and $\mathrm{P}_{\mathrm{F}} \times$ SLOPE was represented by a polygonal line with a slope of 1 and a ceiling for both nodulation types in the three experimental years, while the fitness in Lee(+) was higher than Lee(-) (Fig. 5). When $P_{A}$ and $P_{F} \times S L O P E$ were normalized to $\left(P_{A}-P_{S}\right)$ $/ P_{\text {Amax }}\left(P_{A \max }=P\right.$ at the ceiling) and $\left(P_{F} \times S L O P E\right) / P_{\text {Amax }}$, respectively (Fig. 1), all observations were appropriately described by the same line with higher fitness $\left(r^{2}=0.954\right)$ (Fig. 6).

Contributions of $\mathrm{P}_{\mathrm{A}}$ to seed production

Seed dry weight was asymptotically increased with increasing $\mathrm{P}_{\mathrm{A}}$, and the plateaus were similar for all Lee(+) treatments under different amounts of $\mathrm{N}_{\mathrm{F}}$ across three years, but for Lee(-) treatments, the height of the curves in the seed weight significantly differed according to $\mathrm{N}_{\mathrm{F}}$, and the plateaus were higher with higher $\mathrm{N}_{\mathrm{F}}$ (Fig. 7, upper panels). On the contrary, $\mathrm{N}_{\mathrm{A}}$ consistently increased seed dry weight, irrespective of nodulation type $\left[\mathrm{Lee}(+)\right.$ or Lee(-)] and differing $\mathrm{P}_{\mathrm{F}}$ values in all years (Fig. 7, lower panels).

Multiple regression analyses of seed dry weight and two independent variables, $\mathrm{N}_{\mathrm{A}}$ and $\mathrm{P}_{\mathrm{A}}$, for Lee(+) and Lee(-) plants across all three years showed that the contribution of $\mathrm{P}_{\mathrm{A}}$ to seed dry weight in Lee(+) plants (68.0\%) was much higher than in Lee(-) plants (23.4\%) with high $r^{2}$ 
(Table 1). Conversely, in Lee(-) plants, the contribution of $\mathrm{N}_{\mathrm{A}}(76.6 \%)$ was much higher than in Lee(+) plants (32.0\%). Seed weight in Lee(+) plants was therefore highly dependent on $\mathrm{P}_{\mathrm{A}}$, while in Lee(-) plants, it depended on $\mathrm{N}_{\mathrm{A}}$.

Table 1

Multiple regression analysis and the contribution of nitrogen assimilation (NA)

and phosphorus assimilation (PA) to seed yield in nodulated [Lee $(+)]$ and nonnodulated [Lee $(-)]$ soybeans from results in three-year experiments

\begin{tabular}{|lllll|}
\hline & Multiple regression equation & $r^{2}$ & \multicolumn{2}{c|}{ Contribution ratio (\%) } \\
\hline & & & $\mathrm{N}_{\mathrm{A}}$ & $\mathrm{P}_{\mathrm{A}}$ \\
\hline Lee $(+)$ & Yield $=2.67 \mathrm{~N}_{\mathrm{A}}+65.2 \mathrm{P}_{\mathrm{A}}+6.03$ & 0.846 & 32.0 & 68.0 \\
\hline Lee $(-)$ & Yield $=7.49 \mathrm{~N}_{\mathrm{A}}+27.8 \mathrm{P}_{\mathrm{A}}-0.12$ & 0.937 & 76.6 & 23.4 \\
\hline
\end{tabular}

The effect of $\mathrm{P}$ on $\mathrm{N}_{\mathrm{Amax}}$ and $\mathrm{N}_{\mathrm{FIX}}$

The estimated values of $\mathrm{N}_{S}$ were very low for both Lee(+) and Lee(-) isolines (Table 2 and Fig. 2). The relationship between $\mathrm{N}_{\mathrm{A}}$ and $\mathrm{N}_{\mathrm{F}}$ was effectively explained by the model of nodulated isolines under various $\mathrm{P}_{\mathrm{F}}$ rates with high $r^{2}[0.590-0.985$ in Lee(+) and $0.947-0.998$ in Lee $(-)]$, except for P0 treatments $\left[r^{2}=0.092-0.569\right.$ in Lee $(+)$ and $r^{2}=0.122-0.453$ in Lee(-)] (Table 2). 
Table 2

Parameter estimates (NFIXmax, NAmax, NS, and s - 1) and coefficient of fitness ( $r 2$ ) from the quantitative $\mathrm{N}$ model based on results for the two isolines [Lee $(+)$ and Lee $(-)$ ] in three years observations. NFIXmax is maximum nitrogen fixation (NFIX), NAmax is maximum nitrogen assimilation, NS is available soil nitrogen, and $s-1$ is reduction of NFIX due to increasing NF. See Figure 2 for the model

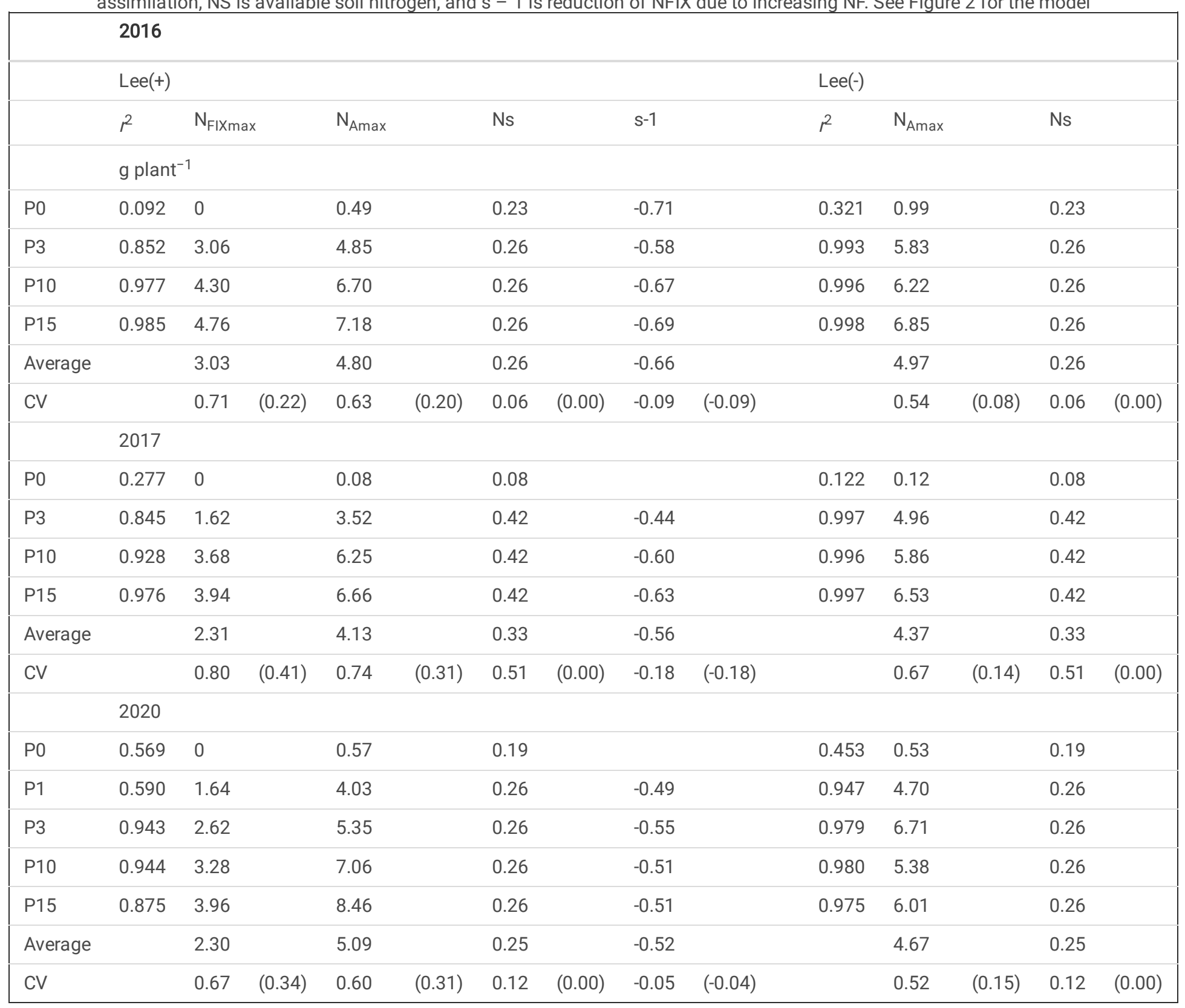

The estimated $\mathrm{N}_{\text {Amax }}$ and $\mathrm{N}_{\mathrm{FIXmax}}$ of Lee(+) plants increased significantly and asymptotically with $\mathrm{P}_{\mathrm{F}}$ (Fig. 8, upper panels), although these relationships differed between the three experimental years. However, the relative $\mathrm{N}_{\mathrm{Amax}}$ and $\mathrm{N}_{\mathrm{FIXmax}}$ (the ratio to the maximum value for each year) were able to be expressed with same line, regardless of year (Fig. 8, lower panels). $N_{A m a x}$ defined as the highest $N_{A}$ in each $P_{F}$ treatment, similarly increased with $P_{A}$ regardless of nodulation type and experimental year (Fig. 9, upper). $N_{F I X m a x}$ of Lee $(+)$ plants increased with $P_{A}$ regardless of experimental year (Fig. 9, lower). The variations of $s-1$ (the change in the rate of reduction of $N_{F I X}$ by $N_{F}$ ) were relatively small (coefficient of variation $[C V]=0.05-0.18$ ) under different $P_{F}$ rates $($ Table 2 ).

\section{Discussion}

Modelling the quantitative relationship between $\mathrm{P}_{\mathrm{A}}$ and $\mathrm{P}_{\mathrm{F}}$

The relationship between $\mathrm{P}_{\mathrm{A}}$ and $\mathrm{P}_{\mathrm{F}}$, regardless of nodulation type, was approximated by the Case 3 model, whereby $\mathrm{P}_{\mathrm{A}}$ increased linearly with $P_{F}$, then reached a ceiling line (Fig. 1 and 3). The SLOPE increased linearly with $N_{F}$ at low concentrations of applied $N$, and converged towards a constant rate under high concentrations of $\mathrm{N}_{\mathrm{F}}$ (Fig. 4). This pattern suggested that an increase in the root mass as root length by $\mathrm{N}$ application (Arima et al. 2000), which promoted root contact with soil, resulted in an increase in P absorption. Soybean root weight was 
around $17 \%$ of shoot weight (Ordóñeza et al. 2020) and $19-29 \%$ with $10 \%$ of CV estimated in plants of the split root experiment under different nitrate nitrogen rate (Xia et al. 2017). From the result, when root weights were estimated by the observed shoot weight at the maximum for each treatment of $\mathrm{N}$ rate $\times 0.17$ (root per shoot weight) as a case and the relationship between SLOPE and the root weight was plotted, SLOPE increased with an increase in root weight, while the relationship differed between nodulation types (Fig. 10). Hence, it was suggested that SLOPE changed by the root weight to contribute to contact with soil. The difference in the response of SLOPE to root weight between nodulation types was possible to result from that in root length, because an inverse relationship between nodule mass and total root length including different nodulation types was observed and hence root length in nodulated soybean might be shorter than that in nonnodulated soybean at same root weight (Cassman et al. 1980). After roots were distributed throughout the bulk pot soil due to adequate $\mathrm{N}$ supply, a ratio of absorbed to supplied $\mathrm{P}$ from fertilizer and soil P (SLOPE) converged towards a constant rate in each experimental year. The constant rate would reflect the phosphate absorption coefficient of the soil. The ceiling formed at higher $\mathrm{N}$ applications in the relationship between assimilated $P$ and supplied $P$ from fertilizer indicated that at most less than $30 \%$ of supplied $P$ was available for the plants in both soybean nodulation types in the soil. Hence, it was suggested that $\mathrm{N}$ fertilizer alters $\mathrm{P}$ absorption via root development under limited $\mathrm{N}$ applications in soybeans, although root mass and length density were not directly observed in this experiment.

Applied $\mathrm{P}$ in the pots was mixed uniformly into soils and root distribution was limited. However, applied $\mathrm{P}$ in the field is mainly located in cultivated soil layers, which change based on cultivation procedures. The shape of the regression of SLOPE below the ceiling and $\mathrm{N}_{\mathrm{F}}$ at which the ceiling is reached (Fig, 4) would change depending on P distributions in the soil. Therefore, in the field a factor of $P$ distribution in the soil should be considered in the model. However, in higher P soils in cultivated soil layers, such as the fields in Japan which have had P fertilizer applied conventionally over long periods of time, the relationship between assimilated and applied $\mathrm{P}$ would be indicated only by a constant ceiling line representing soil P without SLOPE in a model even if under diverse applied P conditions (Kakiuchi and Kamiji 2015).

Contributions of $\mathrm{P}_{\mathrm{A}}$ to $\mathrm{N}_{\mathrm{A}}$ and seed production

Absorbed $\mathrm{P}$ from soils $\left(\mathrm{P}_{\mathrm{A}}\right)$ increased the seed dry weight of both nodulation types, although the increase was dependent on $\mathrm{N}_{\mathrm{F}}$ for the nonnodulated isoline (Fig. 7). This suggested that for the non-nodulated isoline, N, rather than $\mathrm{P}$, is a limiting factor for seed production. The higher contribution of $\mathrm{N}_{\mathrm{A}}$ to the seed yield in Lee(-) was also indicated by a multiple regression analysis (Table 1). Contrary to the effect of $\mathrm{P}_{\mathrm{A}}$ on yield, $\mathrm{N}_{\mathrm{A}}$ was closely related to seed production under a wide range of $\mathrm{P}_{\mathrm{F}}$ values in both nodulated and non-nodulated isolines (Fig. 7). The close relationship between seed yield and $\mathrm{N}_{\mathrm{A}}$ can be followed by the fact that, in soybeans, assimilated $\mathrm{N}$ is mainly distributed to the seeds, so seed yield directly reflects the quantity of $\mathrm{N}$ assimilation (Jin et al. 2011; Kakiuchi and Kobata 2017; Salvagiotti et al. 2008; Zhao et al. 2014). In Lee(+) plants, $N_{A}$ is secured by the nodules, and seed dry weight can increase immediately following an increase in $P_{A}$, but in Lee(-) plants, $\mathrm{N}_{\mathrm{A}}$ is limited only by applied and soil $\mathrm{N}$, so the response of seed weight to $\mathrm{P}_{\mathrm{A}}$ is restricted by $\mathrm{N}_{\mathrm{A}}$. $\mathrm{N}_{\mathrm{Amax}}$ of both isolines and $\mathrm{N}_{\mathrm{FIXmax}}$ of Lee(+) plants increased with $P_{A}$, regardless of experimental year (Fig. 9). Hence, the limitation of $N$ assimilation, seems to depend on $P$ supply. However, as a result, assimilated $\mathrm{P}$ seemed to indirectly contribute to seed production via the effects of $\mathrm{P}$ on $\mathrm{N}_{\mathrm{A}}$ which consisted of absorbed and fixed $\mathrm{N}$.

\section{Conclusion}

Absorbed $\mathrm{P}$ by soybean plants can be indicated by a function of applied $\mathrm{P}$ by excluding $\mathrm{P}$ retained in soils significantly influenced by $\mathrm{N}_{\mathrm{F}}$. Furthermore, assimilated P effects seed production via $\mathrm{N}_{\mathrm{A}}$ behavior, consisting of $\mathrm{N}$ absorption from fertilizer, soil, and fixed $\mathrm{N}$. We believe that our model concept for $\mathrm{P}$ assimilation will contribute to the development of sub-models for saving fertilizer use and planning in soybeans.

\section{Abbreviations}

$\mathrm{N}_{\mathrm{A}}$, nitrogen assimilation; $\mathrm{N}_{\mathrm{Amax}}$, maximum nitrogen assimilation; $\mathrm{N}_{\mathrm{F}}$, applied fertilizer nitrogen; $\mathrm{N}_{\mathrm{FIX}}$, fixed nitrogen; $\mathrm{N}_{\mathrm{FIXmax}}$, maximum fixed nitrogen ; $N_{S}$, available soil nitrogen; $P_{A}$, phosphorus assimilation; $P_{A m a x}$, maximum phosphorus assimilation; $P_{F}$, applied phosphorus by fertilizer; $P_{S}$, available phosphorus in soil.

\section{Declarations}

\section{Acknowledgments}

We are grateful to Dr. Shingo Matsumoto, Faculty of Life and Environmental Science, Shimane University for his valuable comments and suggestions. 


\section{References}

1. Aguilar SA, van Diest A (1981) Rock-phosphate mobilization induced by the alkaline uptake pattern of legumes utilizing symbiotically fixed nitrogen. Plant Soil 61:27-42. https://doi.org/10.1007/BF02277360

2. Arima S, Harada J, Asanuma S, Miahara M (2000) Analysis of root growth characteristics based on a pipe-model theory and distribution of root nodules in soybean (Glycine max Merr.). Japan J Crop Sci 69:95-101. https://doi.org/10.1626/jcs.69.95

3. Auxtero E, Maderia M, Sousa E (2008) Phosphorus sorption maxima and desorbability in selected soils with andic properties from the Azores. Portugal Geoderma 144:535-544. https://doi:10.1016/j.geoderma.2008.01.008

4. Caassen N, Barber SA (1976) Simulation model for nutrient uptake from soil by a growing plant root system. Agron J 68:961-964. https://doi.org/10.2134/agronj1976.00021962006800060030x

5. Cassman KG, Whitney AS, Stockinger KR (1980) Root growth and dry matter distribution of soybean as affected by phosphorus stress, nodulation, and nitrogen source. Crop Sci 20:239-244. https://doi.org/10.2135/cropsci1980.0011183X002000020022x

6. Chaudhary MI, Fujita K (1998) Comparison of phosphorus deficiency effects on the growth parameters of mashbean, mungbean, and soybean. Soil Science and Plant Nutr 44:19-30. https://doi.org/10.1080/00380768.1998.10414423

7. Chaudhary MI, Adu-Gyamfi JJ, Saneoka H et al (2008) The effect of phosphorus deficiency on nutrient uptake, nitrogen fixation and photosynthetic rate in mashbean, mungbean and soybean. Acta Physiol Plant 30:537-544. https://doi.org/10.1007/s11738-008-0152-8

8. Cordell D, Drangert J, White S (2009) The story of phosphorus: Global food security and food for thought. Glob Environ Change 19:292305. https://doi.org/10.1016/j.gloenvcha.2008.10.009

9. Cordell D (2021) The story of phosphorus: 7 reasons why we need to transform phosphorus use in the global food system. Phosphorus Futures. Available from: http://phosphorusfutures.net/the-phosphorus-challenge/the-story-of-phosphorus-8-reasons-why-we-need-torethink-the-management-of-phosphorus-resources-in-the-global-food-system/

10. de Mooy CJ, Pesek J (1966) Nodulation responses of soybeans to added phosphorus, potassium, and calcium salts. Agron J 58:275280. https://doi.org/10.2134/agronj1966.00021962005800030009x

11. Fehr WR, Caviness CE (1977) Stages of soybean development. Spec Rep lowa State Univ 80:1-12

12. Föhse D, Claassen N, Jungk A (1991) Phosphorus efficiency of plants. II. Significance of root radius, root hairs and cation-balance for phosphorus influx in seven plant species. Plant Soil 132:261-272. https://www.jstor.org/stable/42936992

13. Fujita K, Tanaka A (1982) Effect of combined nitrogen on accumulation and translocation of fixed-and combined-nitrogen in soybeans. Jpn J Soil Sci Plant Nutr 53:30-34

14. Israel DW (1987) Investigations of the role of phosphorus in symbiotic dinitrogen fixation. Plant Physiol 84:835-840. https://doi.org/10.1104/pp.84.3.835

15. Jin J, Liu X, Wang G et al (2011) Leaf nitrogen status as a main contributor to yield improvement of soybean cultivars. Agron J 103:441448. https://doi.org/10.2134/agronj2010.0344

16. Kakiuchi J, Kamiji Y (2015) Relationship between phosphorus accumulation and dry matter production in soybeans. Plant Prod Sci 18:344-355. https://doi.org/10.1626/pps.18.344

17. Kakiuchi J, Kobata T (2017) A quantitative method for analyzing nitrogen assimilation in soybeans. Crop Sci 57:903-913. https://doi.org/10.2135/cropsci2016.05.0373

18. Kitou M, Matsuoka H, Kondo Y, Uchida N (2009) Comparison of low P tolerant leguminous plants using akadama soil, and effect of root development on low P tolerance of Sesbania cannabina. Jpn J Soil Sci Plant Nutr 80:487-493. https://doi.org/10.20710/dojo.80.5_487

19. Konno T, Saito M, Ishii K (1990) Relationship among nodulation, shoot growth, and nutrient status of soybean. Jpn J Soil Sci Plant Nutr 61:396-403. https://doi.org/10.20710/dojo.61.4_396

20. Matsunaga R, Matsumoto S (1984) Phosphorus and potassium response of wild and cultivated soybeans. Jpn J Crop Sci 53:131-138. https://doi.org/10.1626/jcs.53.131

21. Matsunaga T, Shiozaki H (1989) Sulfuric acid-hydrogen peroxide digestion for the determination of total nitrogen in plan material containing nitrate nitrogen. J Sci Soil Anim Fert Jpn 60:458-460. https://doi.org/10.20710/dojo.60.5_458

22. Marschner H (1995) Mineral nutrition of higher plants. second edition. Academic Press, London

23. Murphy J, Riley JP (1962) A modified single solution method for the determination of phosphate in natural waters. Anal Chim Acta 27:31-36. https://doi.org/10.1016/S0003-2670(00)88444-5

24. Nelson DW, Sommers LE (1973) Determination of total nitrogen in plant material. Agron J 65:109-112. https://doi.org/10.2134/agronj1973.00021962006500010033x 
25. Ordóñeza RA, Archontoulisa SV, Martinez-Feriab R, Hatfieldc JL, Wrighta EE, Castellanoa MJ (2020) Root to shoot and carbon to nitrogen ratios of maize and soybean crops in the US Midwest. Europ J Agron 120:126-130. https://doi.org/10.1016/j.eja.2020.126130

26. Pazderink DL, Graham PH, Orf JH (1997) Variation in the pattern of nitrogen accumulation and distribution in soybean. Crop Sci 37:1482-1486. https://doi.org/10.2135/cropsci1997.0011183X003700050011x

27. Rotundo JL, Borrás L, Bruin JD et al (2014) Soybean nitrogen uptake and utilization in Argentina and United States cultivars. Crop Sci 54:1153-1165. https://doi.org/10.2135/cropsci2013.09.0618

28. Rubaek GH, Sibbesen E (1995) Soil phosphorus dynamics in a long-term filed experiment at Askov. Biol Fertil Soils 20:86-92. https://doi.org/10.1007/BF00307847

29. Sathiyavani E, Prabaharan NK, Krishna Surendar K (2017) Role of mineral nutrition on root growth of crop plants - A Review. Int J Curr Microbiol App Sci 6:2810-2837. https://doi.org/10.20546/ijcmas.2017.604.324

30. Salvagiotti FKG, Cassman JE, Specht DT et al (2008) Nitrogen uptake, fixation and response to fertilizer N in soybeans: A review. Field Crops Res 108:1-13. https://doi.org/10.1016/j.fcr.2008.03.001

31. Schulze J, Temple G, Temple SJ et al (2006) Nitrogen fixation by white lupin under phosphorus deficiency. Ann Bot 98:731-740. https://doi.org/10.1093/aob/mcl154

32. Silberbush M, Barber SA (1983) Sensitivity of simulated phosphorus uptake to parameters used by a mechanistic-mathematical model. Plant Soil 74:93-100. https://doi.org/10.1007/BF02178744

33. Sinclair TR, de Wit CT (1976) Analysis of the carbon and nitrogen limitations to soybean yield. Agron J 68:319-324. https://doi.org/10.2134/agronj1976.00021962006800020021x

34. Singh KK, Srinivasarao C, Ali M (2005) Root growth, nodulation, grain yield, and phosphorus use efficiency of lentil as influenced by phosphorus, irrigation, and inoculation. Soil Sci Plant Anal 36:1919-1929. https://doi.org/10.1081/CSS-200062501

35. Sleight DM, Sander DH, Peterson GA (1984) Effect of fertilizer phosphorus placement on the availability of phosphorus. Soil Sci Soc Am J 48:336-340. https://doi.org/10.2136/sssaj1984.03615995004800020023x

36. Stewart JWB, Tiessen H (1987) Dynamics of soil organic phosphorus. Biogeochemistry 4:41-60. https://doi.org/10.1007/BF02187361

37. Tanikawa N (2016) Effect of available phosphorus or phosphorus fractions on paddy rice growth in tillering stage. Tohoku Agric Res 69:11-12

38. Tanaka A, Fujita K, Tanaka Y (1980) Effect of shading on nitrogen fixation and combined nitrogen absorption in soybean. Jpn J Soil Sci Plant Nutr 51:281-284

39. Theodorou ME, Plaxton WC (1993) Metabolic adaptations of plant respiration to nutritional phosphate deprivation. Plant Physiol 101:339-344. https://doi.org/10.1104/pp.101.2.339

40. Thornley JHM (1976) Mathematical Models in Plant Physiology. Academic Press, New York

41. White PJ, Veneklaas EJ (2012) Nature and nurture: the importance of seed phosphorus content. Plant Soil 357:1-8. https://doi.org/10.1007/s11104-012-1128-4

42. Xia X, Ma C, Dong S, Xu Y, Gong Z (2017) Effects of nitrogen concentrations on nodulation and nitrogenase activity in dual root systems of soybean plants. Soil Sci Plant Nut 63:470-482. https://doi.org/10.1080/00380768.2017.1370960

43. Zhao X, Zheng SH, Arima S (2014) Influence of nitrogen enrichments during reproductive growth stage on leaf nitrogen accumulation and seed yield in soybean. Plant Prod Sci 17:209-217. https://doi.org/10.1626/pps.17.209

\section{Figures}

\section{Figure 1}

Models of the relationships between assimilated $\left(P_{A}\right)$ and applied phosphorus $\left(P_{F}\right)$ (left panel), between $P_{A}$ and $P_{F} \times S L O P E$, where $S L O P E=$ $\left(P_{A}-P_{S}\right) / P_{F}$ and $P_{S}$ is soil $P$; SLOPE represents $P_{F}$ use efficiency for $P_{A}$ (middle panel), and a normalized relationship that $y$-axis and $x$-axis in the relationship of middle panel are normalized del by $\left(P_{A}-P_{S}\right) / P_{A m a x}$ and by $\left(P_{F} \times S L O P E\right) / P_{A m a x}$, respectively, where $P_{A m a x}$ is the height of the ceiling (right panel). Three predicted cases (Cases 1, 2, and 3) of the relationship are shown

\section{Figure 2}

Page 9/11 
The nitrogen quantitative model for the relationship between the nitrogen assimilation $\left(\mathrm{N}_{\mathrm{A}}\right)$ or fixation ( $\left.\mathrm{N}_{\mathrm{FIX}}\right)$ and the quantity of nitrogen applied as fertilizer $\left(\mathrm{N}_{\mathrm{F}}\right)$ for nodulated [Lee(+)] (upper left) and non-nodulated [Lee(-)] soybeans (upper right) (Kakiuchi and Kobata 2017) and data fitted to the model for the Lee(+) (lower left) and Lee(-) (lower right) isolines in three years experiments. Each observed data point represents the mean of three replicates. $\mathrm{N}_{S}$ indicates amount of available soil nitrogen, $\mathrm{N}_{\mathrm{Amax}}$ indicates maximum nitrogen assimilation by plants, and $\mathrm{N}_{\mathrm{FIXmax}}$ indicates maximum nitrogen fixation. When $\mathrm{N}_{\mathrm{F}}>\left(\mathrm{N}_{\mathrm{Amax}}-\mathrm{N}_{\mathrm{S}}\right)$, then $\mathrm{N}_{\mathrm{A}}=\mathrm{N}_{\mathrm{Amax}}$ and when $\mathrm{N}_{\mathrm{F}}<\left(\mathrm{N}_{\mathrm{Amax}}-\mathrm{N}_{\mathrm{S}}\right)$, then $\mathrm{N}_{\mathrm{A}}=$ $s N_{F}+\left(N_{S}+N_{F I X}\right)$, where $N_{F I X}=N_{A}-\left(N_{F}+N_{S}\right)$ and $N_{F I X}=(s-1) N_{F}+N_{F I X m a x}$

\section{Figure 3}

Relationships between assimilated $\mathrm{P}\left(\mathrm{P}_{\mathrm{A}}\right)$ and the quantity of $\mathrm{P}$ applied as fertilizer $\left(\mathrm{P}_{\mathrm{F}}\right)$ in Lee $(+)$ and Lee $(-)$ isolines, according to the model (Case 3) (Fig. 1, left). Each data point represents the mean of three replicates

\section{Figure 4}

The ratio of assimilated $P\left(P_{A}\right)$ to applied $P\left(P_{F}\right)$ plus soil $P\left(P_{S}\right)\left[S L O P E=\left(P_{A}-P_{S}\right) / P_{F}\right]$ and applied $N\left(N_{F}\right)$ in Lee $(+)$ and Lee $(-)$ isolines. SLOPE was derived from data in Fig. 3 when observed data was fitted to Case 3 in Fig. 1 (middle)

\section{Figure 5}

Relationships between assimilated phosphorus $\left(P_{A}\right)$ and available $P$ derived from applied $P\left(P_{F} \times S L O P E\right)$ in Lee $(+)$ and Lee $(-)$ isolines, according to the model (Case 3) (Fig. 1, middle). Each data point represents the mean of three replicates

\section{Figure 6}

A normalized model of the relationships between the quantity of $P$ applied as fertilizer $\left(P_{F}\right)$ and assimilated $\left(P_{A}\right)$ in Lee $(+)$ and Lee $(-)$ isolines (Fig. 1, left). Each data point represents the mean of three replicates

\section{Figure 7}

Relationships between seed dry weight and assimilated phosphorus $\left(\mathrm{P}_{\mathrm{A}}\right)$ (upper) or nitrogen $\left(\mathrm{N}_{\mathrm{A}}\right)($ lower) in Lee(+) and Lee $(-)$ isolines. Each data point represents the mean of three replicates. The coefficients in the equation $y=a[1-b \exp (-c x)]$ and the coefficient of determination $\left(r^{2}\right)$ for Lee(-) presented in the middle graphs are as follows, in the format $\left(a, b, c\right.$, and $\left.r^{2}\right)$ : for 2016, N0 (0.01, 251, 5.3, and 0.776); N0.5 (5.6, $1.1,77$, and 0.658); N2.0 (20, 0.98, 14, and 0.999); N8.0 (45, 1.2, 16, and 0.966); for 2017, N0 (3.8, 1.4, 261, and 0.945); N0.5 (11, 0.99, 17, and 0.996); N2.0 (28, 1.0, 15, and 0.997); N8.0 (78, 1.0, 3.7, and 0.999); for 2020, N0 (4.6, 0.8, 48, and 0.827); N2.0 (28, 1.1, 17, and 0.994); N4.0 $(47.5,1.0,12$, and 0.996$)$; N8.0 (57, 1.0, 8.3, and 0.990); N12.0 (60, 1.1, 9.3, and 0.958)

\section{Figure 8}

Relationships between maximum nitrogen assimilation $\left(\mathrm{N}_{\mathrm{Amax}}\right)$ or fixation $\left(\mathrm{N}_{\mathrm{FIXmax}}\right)$ (upper), and the $\mathrm{N}_{\mathrm{Amax}}$ or $\mathrm{N}_{\mathrm{FIXmax}}$ values as ratios of the maximum for each year in Lee(+) (lower) and the quantity of phosphorus applied as fertilizer $\left(P_{F}\right)$. Each data point represents the mean of three replicates. Coefficients in the equation $y=a[1-b \exp (-c x)]$ are indicated in the form $\left(a, b, c\right.$, and $\left.r^{2}\right)$ and are presented in the graphs

\section{Figure 9}


The relationship between maximum nitrogen assimilation $\left(\mathrm{N}_{\mathrm{Amax}}\right)$ (upper) or maximum nitrogen fixation ( $\left.\mathrm{N}_{\mathrm{FIXmax}}\right)$ (lower) and assimilated phosphorus $\left(\mathrm{P}_{\mathrm{A}}\right)$. Each data point represents the mean of three replicates

\section{Figure 10}

SLOPE represented $P_{F}$ use efficiency for $P_{A}$ (Fig. 1) and estimated root weight under different applied $N\left(N_{F}\right)$ in Lee(+) and Lee(-). The root weight was estimated from shoot weight at the maximum in each $\mathrm{N}_{\mathrm{F}}$ rate $\times 0.17$ (Ordóñeza et al. 2020) 